\title{
Respiratory panic disorder subtype and sensitivity to the carbon dioxide challenge test
}

\footnotetext{
A.M. Valença ${ }^{1}$, A.E. Nardi ${ }^{1}$, I. Nascimento ${ }^{1}$, W.A. Zin ${ }^{2}$ and M. Versiani ${ }^{1}$
}

\author{
'Laboratório de Pânico e Respiração, Instituto de Psiquiatria, \\ Universidade Federal do Rio de Janeiro, Rio de Janeiro, RJ, Brasil \\ 2Laboratório de Fisiologia da Respiração, Instituto de Biofísica Carlos Chagas Filho, \\ Universidade Federal do Rio de Janeiro, Rio de Janeiro, RJ, Brasil
}

\section{Correspondence \\ A.M. Valença \\ R. da Cascata, 13, Apto 501 \\ 20530-080 Rio de Janeiro, RJ \\ Brasil \\ Fax: +55-21-521-6147 \\ E-mail: avalen@uol.com.br \\ Research supported by $\mathrm{CNPq}$ (No. 300500/93-9).}

Received June 20, 2001 Accepted May 7, 2002

\section{Abstract}

The aim of the present study was to verify the sensitivity to the carbon dioxide $\left(\mathrm{CO}_{2}\right)$ challenge test of panic disorder (PD) patients with respiratory and nonrespiratory subtypes of the disorder. Our hypothesis is that the respiratory subtype is more sensitive to $35 \% \mathrm{CO}_{2}$. Twenty-seven PD subjects with or without agoraphobia were classified into respiratory and nonrespiratory subtypes on the basis of the presence of respiratory symptoms during their panic attacks. The tests were carried out in a double-blind manner using two mixtures: 1) 35\% $\mathrm{CO}_{2}$ and $65 \% \mathrm{O}_{2}$, and 2) $100 \%$ atmospheric compressed air, $20 \mathrm{~min}$ apart. The tests were repeated after 2 weeks during which the participants in the study did not receive any psychotropic drugs. At least 15 of $16(93.7 \%)$ respiratory PD subtype patients and 5 of $11(43.4 \%)$ nonrespiratory $\mathrm{PD}$ patients had a panic attack during one of two $\mathrm{CO}_{2}$ challenges $(\mathrm{P}=0.009$, Fisher exact test). Respiratory PD subtype patients were more sensitive to the $\mathrm{CO}_{2}$ challenge test. There was agreement between the severity of PD measured by the Clinical Global Impression (CGI) Scale and the subtype of PD. Higher CGI scores in the respiratory PD subtype could reflect a greater sensitivity to the $\mathrm{CO}_{2}$ challenge due to a greater severity of PD. Carbon dioxide challenges in PD may define PD subtypes and their underlying mechanisms.

\author{
Key words \\ - $\mathrm{CO}_{2}$ \\ - Anxiety \\ - Breathing \\ - Respiration
}

\section{Introduction}

The inhalation of high carbon dioxide $\left(\mathrm{CO}_{2}\right)$ concentrations has consistently been shown to provoke anxiety and panic attacks in panic disorder (PD) patients (1-7). Among the numerous agents capable of inducing panic in patients with $\mathrm{PD}, \mathrm{CO}_{2}$ offers significant advantages. It is easily administered, well tolerated, and one of the most reliable panicogens (8). The two most common meth- ods used are prolonged (15 min) inhalation of $5 \% \mathrm{CO}_{2}$ and one or two vital capacity inhalations of $35 \% \mathrm{CO}_{2}$ and $65 \% \mathrm{O}_{2}$. The $35 \% \mathrm{CO}_{2}$ technique has been found to differentiate between PD patients and controls, displaying marked specificity for PD (8-10).

Briggs et al. (11) studied the descriptions of the latest severe panic attack of 1108 PD patients who were divided into two groups according to the presence of prominent respiratory symptoms. The group with promi- 
nent respiratory symptoms suffered more spontaneous panic attacks and seemed to respond better to imipramine, whereas patients with the nonrespiratory subtype suffered more situational panic attacks and seemed to respond better to alprazolam.

Biber and Alkin (12) used 35\% $\mathrm{CO}_{2}-65 \%$ $\mathrm{O}_{2}$ as a challenge test in 51 PD patients, who were divided into respiratory $(\mathrm{N}=28)$ and nonrespiratory $(\mathrm{N}=23)$ subtypes by their symptom profiles. Twenty-two (79\%) of the patients in the prominent respiratory symptom subtype and 11 (48\%) of the patients in the nonrespiratory subtype group experienced a panic attack. Data suggest that respiratory PD subtype patients may be more sensitive to a $\mathrm{CO}_{2}$ challenge, experiencing more panic attacks after inhaling this gas mixture according to the false suffocation alarm hypothesis (13).

The objective of the present study was to determine the sensitivity to the $\mathrm{CO}_{2}$ challenge test of $\mathrm{PD}$ patients with respiratory and nonrespiratory subtypes. Our hypothesis is that respiratory subtype patients are more sensitive to $35 \% \mathrm{CO}_{2}$, having higher rates of panic attacks after inhaling it than nonrespiratory subtype patients.

\section{Patients and Methods}

We selected 27 PD subjects with or without agoraphobia at the Laboratory of Panic and Respiration, Federal University of Rio de Janeiro, who agreed to participate in this protocol. The diagnosis was made using the Structured Clinical Interview (14) for DSMIV (15). The study design of the investigation was explained to the patients and they signed a voluntary written informed consent to participate in the study. The protocol complied with the principles of the Declaration of Helsinki and was approved by our Hospital Ethics Committee.

To participate the subjects were required to be between 18 and 55 years of age and to report at least three panic attacks in the last two consecutive weeks before the first challenge test day. On the day of the tests a urine analysis was performed to determine the possible presence of drugs. Patients had been free of psychotropic drugs for at least one week and tested negative for benzodiazepines and other medications. They underwent physical examination and laboratory tests to ensure they were healthy enough to participate in the study. Exclusion criteria were the existence of any current mental disorder other than PD, a history of psychosis or bipolar disorder, epilepsy, pregnancy, substance abuse within the last 6 months and major medical disorders (uncontrolled thyroid, renal, hepatic, cardiac, pulmonary, or endocrinological diseases as determined by physical examination, vital signs, or laboratory tests).

The clinical symptoms of the most severe recent panic attack were assessed for each patient before the initial visit. The patients were classified into respiratory and nonrespiratory subtypes as described by Briggs et al. (11). Respiratory subtype was considered to be present if at least four of the five respiratory symptoms were recorded as present (choking/smothering sensations; shortness of breath; chest pain/discomfort; numbness/tingling sensations; fear of dying).

As part of the challenge tests two mixtures were used: 1) $35 \% \mathrm{CO}_{2}$ and $65 \% \mathrm{O}_{2}$, and 2) $100 \%$ atmospheric compressed air, 20 min apart under double-blind conditions. The order of the two challenges $\left(35 \% \mathrm{CO}_{2}\right.$ and atmospheric air) was randomized. The challenge tests were repeated after a 2-week period during which no participant in the study received any kind of psychotropic drug. They were asked to exhale as fully as possible, place the mask on their face, take a fast vital capacity breath, inhaling either the $35 \%$ $\mathrm{CO}_{2}$ mixture or the atmospheric compressed air, holding their breath for $8 \mathrm{~s}$ and then exhale. Immediately after, they were asked to repeat the fast vital capacity breath and hold it again for $8 \mathrm{~s}$. The same procedure was repeated after 20 min using the gas mixture 
not used previously. Subjects were informed that we wanted to assess their sensitivity to a carbon dioxide mixture and that they might experience some discomfort like headache, dizziness or symptoms of anxiety. The possibility of a panic attack was not mentioned in order to avoid a cognitive bias related to expectation.

To measure the panic anxiety level we used the Diagnostic Symptom Questionnaire (DSQ) (16), adapted for DSM-IV (15), in which the presence and level of discomfort of panic symptoms experienced after inhalations were rated on a $0-4$-point scale $(0=$ none, $4=$ very severe). On the basis of the DSQ, a $\mathrm{CO}_{2}$-induced panic attack was defined as follows: 1) the presence of four or more DSM-IV panic attack symptoms, 2) at least one DSM-IV cognitive panic symptom (i.e., fear of dying, losing control, or going crazy), 3) sensation of panic or fear resembling real-life panic attacks, and 4) agreement of two medical doctors that the patient had had a clinical panic attack. The DSQ was filled out before and a very short time after $\mathrm{CO}_{2}$ inhalation, just as the patients were able to respond to the questions asked by the investigators. Anxiety symptoms sometimes were present in patients before the $\mathrm{CO}_{2}$ challenge. Therefore, the diagnosis of a panic attack was considered only if the patients fulfilled the four criteria mentioned above. The Clinical Global Impression (CGI) and Hamilton Scale for Anxiety were also used in order to measure the severity of PD and anxiety level, respectively.

\section{Data analysis}

The differences between the respiratory and nonrespiratory groups with respect to age, PD duration, CGI and score on the Hamilton Scale for Anxiety were compared by the Mann-Whitney rank sum test, the sex differences between groups were compared by the chi-square test, and the differences between groups with respect to history of agoraphobia and the presence or absence of panic attacks after the $\mathrm{CO}_{2}$ challenge were compared by the Fisher exact test.

\section{Results}

The patients were 15 women and 12 men with a median age of 39 years. In the respiratory subtype there were 8 women and 8 men with a median age of 33.5 years (25th percentile $=28.0,75$ th percentile $=43.5$ ) and in the nonrespiratory subtype there were 7 women and 4 men with a median age of 40.0 years $(25$ th percentile $=38.0,75$ th percentile $=45.0)$. There were no significant differences between groups in median age $(\mathrm{P}=$ 0.080, Mann-Whitney test). Chi-square analysis of the two subtypes showed no significant differences in sex distribution (Table $1)$.

The median duration of PD was 12 months in the respiratory subtype $(25$ th percentile $=$ $3.5,75$ th percentile $=39.0 ;$ minimum $=1$, maximum $=264$ ) and 24 months in the nonrespiratory subtype $(25$ th percentile $=$ 21.0, 75th percentile $=102.0 ;$ minimum $=2$, maximum $=324)(\mathrm{P}=0.390$, Mann-Whitney test).

Nineteen patients (70.3\%) met the DSMIV criteria for PD with agoraphobia and 8 patients $(29.6 \%)$ met the criteria for PD without agoraphobia. In the respiratory subtype 12 patients had agoraphobia and 4 had not, whereas in the nonrespiratory subtype 7 patients had agoraphobia and 4 had not $(\mathrm{P}=$ 0.670, Fisher exact test). The median CGI of the respiratory subtype was 5 (25th percentile $=5,75$ th percentile $=6 ;$ minimum $=4$, maximum $=6$ ) and the median CGI of the nonrespiratory subtype was 4 (25th percentile $=3,75$ th percentile $=5 ;$ minimum $=3$, maximum $=5)(P=0.014$, Mann-Whitney test). In the respiratory subtype the median score on the Hamilton Scale for Anxiety was 28.5 (25th percentile $=24.0,75$ th percentile $=31.0$ ) whereas in the nonrespiratory subtype this median score was 23.0 (25th per- 
centile $=20.0,75$ th percentile $=27.0$ ). There were no significant differences between groups $(\mathrm{P}=0.110$, Mann-Whitney test).

After the first $\mathrm{CO}_{2}$ challenge 15 of 16 (93.7\%) respiratory PD patients and 5 of 11 (43.4\%) nonrespiratory PD patients had a panic attack ( $\mathrm{P}=0.009$, Fisher exact test). After the second $\mathrm{CO}_{2}$ challenge, 2 weeks later, 14 of $16(87.5 \%)$ respiratory PD patients and 5 of $11(43.4 \%)$ nonrespiratory PD patients had a panic attack $(\mathrm{P}=0.0332$, Fisher exact test). No patient had a panic attack when inhaling atmospheric air. Seven patients of the respiratory subtype and 2 of the nonrespiratory subtype had a panic attack before $8 \mathrm{~s}$ of $\mathrm{CO}_{2}$ inhalation.

\section{Discussion}

Respiratory PD subtype patients were more sensitive to $\mathrm{CO}_{2}$, having higher rates of panic attacks than the nonrespiratory subtype, in agreement with data reported by
Biber and Alkin (12). Only one patient had a panic attack during the first $\mathrm{CO}_{2}$ challenge and not during the second one (Table 1).

Klein's theory (13) could be an alternative explanation for our results. He proposed that panic attacks may occur when the brain's suffocation monitor erroneously signals a lack of useful air, maladaptively triggering an evolved suffocation alarm system. Such dysfunction would make an individual vulnerable to "false suffocation alarms", namely panic attacks. $\mathrm{CO}_{2}$ sensitivity might be higher in respiratory PD subtype patients and would be an aspect of a hypersensitive suffocation detector.

There was agreement between the severity of PD measured by CGI and the type of PD. The median CGI of the respiratory subtype was 5 , whereas in the nonrespiratory subtype the median CGI was 4. PD patients of the respiratory subtype had more severe panic symptoms when compared to the nonrespiratory subtype. The severity of PD

Table 1. Clinical and demographic data of the patients $(\mathrm{N}=27)$.

\begin{tabular}{|c|c|c|c|}
\hline & $\begin{array}{l}\text { Respiratory PD } \\
\text { subtype }\end{array}$ & $\begin{array}{c}\text { Nonrespiratory PD } \\
\text { subtype }\end{array}$ & $P$ \\
\hline Sex & 8 females/8 males & 7 females/4 males & $0.484^{*}$ \\
\hline Median age (years) & $\begin{array}{l}33.5 \\
25 \text { th percentile }=28.0 \\
\text { 75th percentile }=43.5\end{array}$ & $\begin{array}{l}40.0 \\
\text { 25th percentile }=38.0 \\
\text { 75th percentile }=45.0\end{array}$ & $0.080^{* *}$ \\
\hline Median PD duration (months) & $\begin{array}{l}12.0 \\
\text { 25th percentile }=3.5 \\
\text { 75th percentile }=39.0\end{array}$ & $\begin{array}{l}24.0 \\
25 \text { th percentile }=21.0 \\
75 \text { th percentile }=102.0\end{array}$ & $0.390^{* *}$ \\
\hline Median CGI & $\begin{array}{l}5 \\
\text { 25th percentile }=5 \\
\text { 75th percentile }=6\end{array}$ & $\begin{array}{l}4 \\
\text { 25th percentile }=3 \\
\text { 75th percentile }=5\end{array}$ & $0.014^{* *}$ \\
\hline $\begin{array}{l}\text { Median score on the } \\
\text { Hamilton Anxiety Scale }\end{array}$ & $\begin{array}{l}28.5 \\
25 \text { th percentile }=24.0 \\
\text { 75th percentile }=31.0\end{array}$ & $\begin{array}{l}23.0 \\
\text { 25th percentile }=20.0 \\
\text { 75th percentile }=27.0\end{array}$ & $0.110^{* *}$ \\
\hline $\begin{array}{l}\text { Agoraphobia syndrome } \\
\text { Panic attack (first } \mathrm{CO}_{2} \text { challenge) } \\
\text { Panic attack (second } \mathrm{CO}_{2} \text { challenge) }\end{array}$ & $\begin{array}{l}12 \text { yes } / 4 \text { no } \\
15 \text { yes } / 1 \text { no } \\
14 \text { yes } / 2 \text { no }\end{array}$ & $\begin{array}{l}7 \text { yes } / 4 \text { no } \\
5 \text { yes } / 6 \text { no } \\
5 \text { yes } / 6 \text { no }\end{array}$ & $\begin{array}{l}0.670^{* * *} \\
0.009^{* * *} \\
0.0332^{* * *}\end{array}$ \\
\hline
\end{tabular}


could also make patients of the respiratory subtype more sensitive to $\mathrm{CO}_{2}$. On the other hand, the higher $\mathrm{CO}_{2}$ sensitivity in the respitatory PD subtype patients might actually reflect an increased severity of this group (measured by the CGI). A previous report (17) described that the presence of agoraphobia and the greater severity of PD could increase the positive response to the $\mathrm{CO}_{2}$ challenge test (resulting in panic attacks). Perna et al. (5) reported that there was no relationship between $\mathrm{CO}_{2}$ reactivity and the severity of panic-phobic symptomatology. It is important to assume that CGI is a nonspecific scale of mental illness severity. In our study there was no agreement between the existence or severity of agoraphobia and the subtype of PD.

According to DSM-IV (15), PD may involve respiratory symptoms such as dyspnea, and choking/smothering sensations. Briggs et al. (11) reported that the physical symptoms may be similar among individuals, and that an appropriate distinction based on symptoms is the presence or absence of prominent respiratory symptoms (choking/ smothering sensations; shortness of breath; chest pain/discomfort; numbness/tingling sensations; fear of dying).

Respiratory symptoms may play an important role in real-life panic attacks and in $\mathrm{CO}_{2}$-induced panic attacks. In a subgroup of 20 PD patients (18), using a vital capacity inhalation of $35 \% \mathrm{CO}_{2}$, it was found that the symptoms of shortness of breath and choking were significantly correlated with subjective anxiety, suggesting a specific role of respiratory symptoms in PD.

Respiratory panic subtype patients are more sensitive to $\mathrm{CO}_{2}$, having higher rates of panic attacks than patients with the nonrespiratory subtype. Carbon dioxide challenges in PD may help define PD subtypes and their underlying mechanisms. The characterization of PD subtypes through a $\mathrm{CO}_{2}$ challenge may be useful in elucidating biological features, course and response to treatment of anxiety disorders.

\section{Acknowledgments}

The authors thank Ronir R. Luiz for the statistical analysis.

\section{References}

1. Gorman J M, Askanazi J, Liebowitz MR, Fyer AJ , Stein J, Kinney J M \& Klein DF (1984). Response to hyperventilation in a group of patients with panic disorder. American J ournal of Psychiatry, 141: 857861.

2. Gorman JM, Liebowitz MR, Fyer AJ \& Stein J (1989). A neuroanatomical hypothesis for panic disorder. American J ournal of Psychiatry, 146: 148-161.

3. Sanderson WC \& Wetzler S (1990). Five percent carbon dioxide challenge: valid analogue and marker of panic disorder? Biological Psychiatry, 27: 689-701.

4. Griez E, de Loof C, Pols H, Zandbergen J \& Lousberg H (1990). Specific sensitivity of patients with panic attacks to carbon dioxide inhalation. Psychiatry Research, 31: 193-199.

5. Perna G, Battaglia M, Garberi A, Arancio C, Bertani A \& Bellodi L (1994). Carbon dioxide/oxygen challenge test in panic disorder. Psychiatry Research, 52: 159-171.

6. Nardi $A E$, Valença $A M$, Zin $W$ \& Nascimento I (1999). Carbon dioxide induced panic attacks and short term clonazepam treatment. Arquivos de Neuropsiquiatria, 57: 361-365.

7. Nardi AE, Valença AM, Nascimento I, Mezzasalma MA \& Zin WA (2000). Doubleblind acute clonazepam vs. placebo in carbon dioxide-induced panic attacks. Psychiatry Research, 94: 179-184.

8. Papp LA, Klein DF, Martinez J M, Schneier $F$, Cole R, Liebowitz MR, Hollander E, Fyer AJ , J ordan F \& Gorman J M (1993). Diagnostic and substance specificity of carbon-dioxide-induced panic. American J oumal of Psychiatry, 150: 250-257.

9. Verburg K, Griez E, Meijer J \& Pols H (1995). Discrimination between panic disorder and generalized anxiety disorder by
$35 \%$ carbon dioxide challenge. American J oumal of Psychiatry, 152: 1081-1083.

10. Griez E \& Verburg K (1998). Panic provocation with $35 \%$ carbon dioxide: the link with the respiratory system. In: Bellodi L $\&$ Pema G (Editors), The Panic-Respiration Connection. MDM Medical Media Srl, Milano, Italy.

11. Briggs $A C$, Stretch $D D \&$ Brandon $S$ (1993). Subtyping of panic disorder by symptom profile. British J oumal of Psychiatry, 163: 201-209.

12. Biber B \& Alkin T (1999). Panic disorder subtypes: differential responses to $\mathrm{CO}_{2}$ challenge. American J ournal of Psychiatry, 156: 739-744.

13. Klein DF (1993). False suffocation alarms, spontaneous panics, and related conditions. An integrative hypothesis. Archives of General Psychiatry, 50: 306-317.

14. First MB, Spitzer RL, Gibbon $M \&$ Wil- 
liams J BM (1997). Structured Clinical Interview Diagnostic (SCID) for DSM-IV Axis I Disorder-Clinician Version (SCID-CV). American Psychiatric Press, Washington, DC, USA.

15. American Psychiatric Association (1994). Diagnostic and Statistical Manual for Mental Disorders - DSM-IV. 4th edn. American
Psychiatric Press, Washington, DC, USA.

16. Sanderson WC, Rapee RM \& Barlow DH (1989). The influence of an illusion of control on panic attacks via inhalation of $5.5 \%$ carbon dioxide-enriched air. Archives of General Psychiatry, 46: 157-162.

17. Lynch $P$, Bakal D, Whitelaw W, Fung $T \&$ Rose L (1992). Agoraphobic avoidance and panic frequency as predictors of laboratory induced panic attacks. Behaviour Research and Therapy, 30: 591-596.

18. Zandbergen J , Pols H, Fernandez I \& Griez E (1991). An analysis of panic symptoms during hypercarbia compared to hypocarbia in patients with panic attacks. J ournal of Affective Disorders, 23: 131-136. 